\title{
Bases para o tratamento da morbidade em áreas endêmicas de filariose bancroftiana
}

\author{
Rational for morbity management in bancroftian \\ filariasis endemic areas
}

Gerusa Dreyer ${ }^{2}$ e Patrícia Dreyer ${ }^{1}$

\begin{abstract}
Resumo $A$ escolha da terapia mais apropriada para o paciente com bancroftose requer um conhecimento das diversas características clínicas da doença filarial e de sua patogênese. Como resultado de novos testes diagnósticos e avanços clínicos, não apenas nosso entendimento sobre a filariose bancroftiana mudou rapidamente de forma, como as nossas idéias sobre o tratamento. No passado, acreditava-se que a elefantíase era causada pela reação imunológica do hospedeiro ao parasita filarial. Posta dessa maneira, essa forma da doença seria o ponto final de uma inter-relação hóspede-hospedeiro imutável, dada a inexistência de medicamentos ou de condutas que possibilitassem a sua involução nos denominados "indivíduos imunologicamente predispostos". Entretanto, nos últimos anos, surgiram evidências de que o linfedema e a elefantíase tinham outro agente etiológico. O principal fator de evolução para os quadros de linfedema e elefantiásicos seria o desenvolvimento de infecções bacterianas secundárias de repetição. Hoje, é perfeitamente claro que outras formas de terapia de suporte (incluindo a educação e o aconselhamento psicológico) são necessárias e são, muitas vezes, mais importantes que a terapia antiparasitária.
\end{abstract}

Palavras-chaves: Filariose. Wuchereria bancrofti. Morbidade. Controle.

\begin{abstract}
Selection of the most appropriate therapy for the patient with bancroftian filariasis requires a knowledge of the diverse clinical characteristics of filarial disease and their pathogenesis. As a result of new diagnostic tests and clinical advances, our understanding of bancroftian filariasis has changed rapidly, as have our ideas about treatment. In the past, it was believed that elephantiasis was caused by an immunologic reaction of the host to the filarial parasite. From this perspective, elephantiasis was seen as the endpoint of an unalterable relationship between the host and the parasite, and given the absence of effective medication or procedures, affected individuals were considered "immunologically predisposed" to this end-stage disease. In the last few years, however, new evidence has suggested that lymphedema and elephantiasis have another etiologic agent. Namely, the principal factor in the evolution of lymphedema and elephantiasis is the involvement of recurrent secondary bacterial infections. Today, it is clear that other forms of supportive therapy (including education and psychological counseling) are necessary and are often more important than antiparasitic drugs.
\end{abstract}

Key-words: Filariasis. Wuchereria bancrofti. Morbidity. Control.

\footnotetext{
1. Universidade Federal de Pernambuco e 2. Centro de Pesquisas Aggeu Magalhães/FIOCRUZ, Recife, PE.

Suporte financeiro: UNDP/World Bank/WHO Special Programme for Research and Training in Tropical Diseases (TDR), FACEPE, CNPq, Fundação Nacional de Saúde, Fundação Oswaldo Cruz (PAPES) e Organização Não Governamental Amaury Coutinho. Endereço para correspondência: Dr ${ }^{a}$ Gerusa Dreyer. Núcleo de Ensino, Pesquisa e Assistência em Filariose (NEPAF). Departamento de Cirurgia - Hospital das Clínicas/UFPE. Av. Prof. Moraes Rego s/nº, 50670-901 Recife, PE, Brasil. Telefax: 5581 427-6455.

Recebido para publicação em 28/7/99.
} 
A apresentação clínica da filariose bancroftiana é bastante diversificada, variando desde as formas assintomáticas e sintomáticas agudas até as formas crônicas. A doença pode acometer homens e mulheres, atingindo diferentes partes do organismo, como os membros inferiores e os superiores, as mamas, a região escrotal, o pênis e, raramente, a vulva. No homem, o portavoz da doença é o trato urogenital. Na mulher, a elefantíase - a mais desfigurante dentre todas as manifestações crônicas - localiza-se, predominantemente, nos membros inferiores ${ }^{4}$. Estima-se que cerca de 10 a 15\% dos indivíduos infectados irão evoluir para a cronicidade ${ }^{30}$ gerando, no universo dos doentes, uma parcela importante da população que precisará de cuidados especiais relacionados com a recuperação de sua saúde física e mental ${ }^{15}$. No plano individual, considera-se a fase crônica como sendo a mais importante não só do ponto de vista clínico como terapêutico. É nessa fase que têm origem as formas graves e estigmatizantes da filariose linfática, de difícil resolução. Muitas vezes, essas formas são irreversíveis ou solucionadas apenas parcialmente, com reflexos negativos que comprometem a adaptação do paciente à própria sociedade em que vive. O processo inicia-se com a infecção do indivíduo, geralmente quando criança ou adolescente ${ }^{13}$, podendo o mesmo permanecer assintomático por toda a vida ou por um tempo indeterminado, evoluindo, então, para a fase crônica da doença. Nesse sentido, o infectado porém assintomático deve ser alvo também dos programas de controle da morbidade, no sentido de se minimizarem os efeitos da infecção a médio e longo prazos. Se, por um lado, é fato que a mortalidade associada à filariose linfática praticamente inexiste, em contrapartida, é verdadeiro que portar suas formas crônicas é um fardo pesado ${ }^{19} 27$, muitas vezes incapacitante e de relevante importância para a saúde pública nas regiões endêmicas.

Avanços recentes no conhecimento da doença. Relacionados ao verme adulto. Recentemente, com a introdução da ultrasonografia como método para a localização e para a visualização dos vermes adultos vivos de Wuchereria bancrofti ${ }^{2}$, foi possível verificar que o substrato anatomopatológico da infecção filarial é a dilatação dos vasos linfáticos de causa não obstrutiva, sem qualquer reação inflamatória ${ }^{23}$. Adicionalmente, duas outras conseqüências importantes foram geradas pela ultra-sonografia: 1) a identificação de indivíduos amicrofilarêmicos e portadores de vermes adultos ${ }^{18}$, mostrando que todo paciente infectado já tem no mínimo doença subclínica; e 2) a avaliação in vivo da eficácia das drogas antifilariais. Foi então possível testar, com muito mais precisão, o efeito adulticida de drogas, constatando-se que: 1) a única droga com efeito adulticida, a DEC, é só parcialmente efetiva e que doses crescentes não aumentam a sua eficácia ${ }^{24}$;2) a ivermectina, com excelente efeito microfilaricida ${ }^{5}$, não tem qualquer ação nos vermes adultos ${ }^{14}$, mesmo em altas doses ${ }^{6}$. Assim, uma grande parte da população tratada com ambas as drogas, quer isoladas ${ }^{524}$ ou combinadas ${ }^{70}$ persistirá infectada ainda por tempo não determinado, até que a morte do verme ocorra de forma natural. O tempo estimado de vida média do parasito adulto é descrito na literatura como sendo de 5 a 8 anos com bases, de forma indireta, no desaparecimento da microfilária circulante $^{3}$.

A disfunção linfática é produzida pela linfangiectasia, e esta, por sua vez, induzida pelos vermes filariais adultos, vai gerar conseqüências diferentes, dependendo da região anatômica em que os mesmos estejam localizados. Quando a linfangiectasia se localiza em áreas que têm contato com o exterior (membros superiores e inferiores, mama feminina, parede escrotal ou pênis) pode haver predisposição para as infecções bacterianas secundárias ${ }^{12}$. Quando o linfático afetado drena linfa de partes internas do organismo, a bactéria não faz parte do processo. Nesse caso, as anormalidades produzidas estão diretamente relacionadas ao parasita filarial. É o caso da hidrocele, quilocele e quilúria ${ }^{11}$. Em uma pequena parcela da população, o processo inflamatório agudo é causado diretamente pela morte do verme adulto da filária, denominado de linfangite filarial aguda, raramente produzindo linfedema. Quando esse ocorre, é do tipo transitório e com manifestações sistêmicas presentes, na minoria dos indivíduos, com caráter bem menos severo que os surtos de etiologia bacteriana ${ }^{12} 17$.

Assim, diante dos conhecimentos acumulados, temos condições de afirmar que a manifestação clínica, direta ou indiretamente relacionada à infecção filarial, depende da localização do verme adulto, e essa, por sua vez, depende do sexo do indivíduo infectado. Isso é explicado pela localização mais habitual do parasito adulto: nas mulheres, membros inferiores, superiores ${ }^{12} \mathrm{e}$ mamas ${ }^{8}$; no homem, linfáticos do cordão espermático constituem a localização mais freqüente para vermes adultos, o que justifica a 
ocorrência de hidrocele como manifestação clínica prevalente na população masculina ${ }^{22}$.

A etiologia do processo agudo é bacteriana ${ }^{29}$ em cerca de $97 \%$ dos indivíduos acometidos ${ }^{12}$. Hoje, denomina-se esse episódio de dermatolinfoangioadenite ${ }^{25}$. A maioria das bactérias envolvidas no processo agudo é saprófita sensível à penicilina. A soma dos edemas que acompanham os repetidos episódios das infecções bacterianas promove a fibrose e os distúrbios tróficos; produzem o linfedema crônico residual somatório, que pode culminar em elefantíase. À medida que o membro edemacia, ocorre a diminuição ou até mesmo a perda da deambulação normal. Ao edema se soma o aparecimento de pregueamento e de dobras na superfície do membro. Desse modo, estabelecese precariedade de higiene, que facilita o acúmulo de bactérias na pele, predispondo o paciente a infecções secundárias que sobrecarregam um sistema linfático já defeituoso.

A higiene diária com água e sabão previne a maioria das lesões na pele (potenciais portas de entrada) e, consequentemente os episódios agudos. Por outro lado, em alguns pacientes com lesões cutâneas persistentes, além da higiene, será necessário também o uso de cremes antibióticos e antifúngicos (principalmente nas regiões interdigitais). Em conjunto com a educação fisioterápica e a drenagem postural noturna (e ocasionalmente diurna), tais medidas mostraramse eficazes para melhorar o retorno da linfa e diminuir o linfedema. É importante salientar que, uma vez existindo dano linfático, o qual parece ser irreversível, mesmo após o tratamento antiparasitário eficaz, a condição de risco para infecções bacterianas estará presente se as medidas de higiene e suporte forem descontinuadas. Essa prevenção pode ser feita com sucesso a nível individual, em grupos ou na própria comunidade. Material didático para ser utilizado nesse tipo de programa já se encontra disponível na sua versão original em português, com versões para o inglês, creole, francês e espanhol, devendo ser traduzido, no futuro próximo, para o chinês, dialetos indianos e africanos. Adicionalmente, material didático com informações de aplicação prática estará sendo disponibilizado pela Organização Mundial da Saúde e Center for Diseases and Control, Atlanta, EUA, visando-se ao treinamento de profissionais de saúde envolvidos diretamente no controle da morbidade nas áreas endêmicas.

Os distúrbios emocionais são de grande importância para portadores crônicos da doença e podem ser notados, mesmo em uma fase inicial, quando o paciente toma conhecimento de que está infectado, mas ainda sem qualquer manifestação clínica ou apenas com sintomatologia leve e inicial da doença ${ }^{15}$. Isso ocorre devido ao caráter estigmatizante que a doença filarial ainda possui.

Relacionados às microfilárias. A hematúria de origem filarial, predominantemente microscópica, parece ocorrer em cerca de $30 \%$ dos indivíduos adultos do sexo masculino portadores de microfilárias ${ }^{16}$. Ainda não se verificou a ocorrência dessa forma clínica em indivíduos do sexo feminino, crianças e adolescentes. A hematúria desaparece com a eliminação da microfilária circulante estando, portanto, acoplada ao programa de interrupção da transmissão da infecção através do tratamento em massa.

Comentários finais. Mesmo existindo programas bem-sucedidos de controle da transmissão da infecção bancroftiana, é inquestionável o grande contingente de indivíduos já infectados, portadores de linfangiectasias subclínicas ou de formas crônicas ${ }^{19}$. Dentre as formas crônicas, a hidrocele tem repercussão social considerável pois é um fator de reprovação para a seleção de emprego e para a prestação do serviço militar ${ }^{21}$. Assim, portadores de doença linfática clínica e subclínica persistirão ainda por muito tempo, nas áreas nas quais a interrupção da transmissão foi bemsucedida. Isso justifica, do ponto de vista médico e social, a incorporação de programas de morbidade associados aos de interrupção da transmissibilidade ${ }^{28}$. Finalmente, a melhoria das condições de saúde da população através da diminuição de ataques agudos e criação de centros de referência para a correção cirúrgica da hidrocele, dará suporte para uma maior e mais comprometida adesão das comunidades às campanhas de tratamento periódico quimioterápico em massa. Isso pode representar a diferença entre o sucesso e o fracasso do plano de eliminação da filariose linfática no Brasi $^{920}$ e no mundo ${ }^{26}$.

\section{REFERÊNCIAS BIBLIOGRÁFICAS}

1. Amaral F, Dreyer G, Figueredo-Silva J, Norões J, Cavalcanti A, Samico SF, Santos A, Coutinho A. Live adult worms detected by ultrasonography in human bancroftian filariasis. American Journal of Tropical Medicine and Hygiene 50:753-757, 1994.

2. Amaral F, Norões J, Dreyer, G. Uso da ultra-sonografia no diagnóstico da filariose linfática escrotal - relato de dois casos. Revista Brasileira de Radiologia 28: 217-219, 1995. 
3. Andrade LD, Medeiros Z, Pires ML, Pimentel A, Rocha A, Figueredo-Silva J, Coutinho A, Dreyer G. Comparative efficacy of three different diethylcarbamazine regimens in lymphatic filariasis. Transactions of the Royal Society of Tropical Medicine and Hygiene 89:319-321, 1995.

4. Bandyopadhyay L. Lymphatic filariasis and the women of India. Social Science and Medicine 42:1401-1410, 1996.

5. Coutinho A, Dreyer G, Medeiros Z, Lopes E, Machado G, Galdino E, Rizzo JA, Andrade LD, Rocha A, Moura I, Godoy J, Ottesen EA. Ivermectin treatment of bancroftian filariasis in Recife, Brazil. American Journal of Tropical Medicine and Hygiene 50:339-348, 1994.

6. Dreyer G, Addiss D, Norões J, Amaral F, Rocha A, Coutinho A. Ultrasonographic assessment of the adulticidal efficacy of repeated high-dose ivermectin in bancroftian filariasis. Tropical Medicine and International Health 1:427-432, 1996.

7. Dreyer G, Addiss D, Santos A, Figueredo-Silva J, Norões J. Direct assessment in vivo of the efficacy of combined single-dose ivermectin and diethylcarbamazine against adult Wuchereria bancrofti. Transactions of the Royal Society of Tropical Medicine and Hygiene 92:219-222, 1998.

8. Dreyer G, Brandão AC, Amaral F, Medeiros Z, Addiss D. Detection by ultrasound of living adult Wuchereria bancrofti in the female breast. Memórias do Instituto Oswaldo Cruz 91:95-96, 1996.

9. Dreyer G, Coelho G. Filariose linfática: doença potencialmente eliminável. Cadernos de Saúde Pública 13:537-543, 1997.

10. Dreyer G, Coutinho A, Miranda D, Norões J, Rizzo JA, Galdino E, Rocha A, Medeiros Z, Andrade LD, Santos A, Figueredo-Silva J, Ottesen EA. Treatment of bancroftian filariasis in Recife, Brazil: a two year comparative study of the efficacy of single treatments with ivermectin or diethylcarbamazine. Transactions of the Royal Society of Tropical Medicine and Hygiene 89:98-102, 1995.

11. Dreyer G, Figueredo-Silva J, Neafie R, Addiss D. Lymphatic Filariasis. In: Nelson AM, Horsburg CR Jr (eds) Pathology of Emerging Infections 2. American Society for Microbiology, 14:317-342, 1998.

12. Dreyer G, Medeiros Z, Netto MJ, Leal NC, De Castro LG, Piessens WF. Acute attacks in the extremities of persons living in an area endemic for bancroftian filariasis: differentiation of two syndromes. Transactions of the Royal Society of Tropical Medicine and Hygiene 93:413417, 1999.

13. Dreyer G, Norões J, Addiss D, Santos A, Medeiros Z, Figueredo-Silva J. Bancroftian filariasis in a paediatric population: an ultrasonographic study. Transactions of the Royal Society of Tropical Medicine and Hygiene 93:633-636, 1999.

14. Dreyer G, Norões J, Amaral F, Nen A, Medeiros Z, Coutinho A, Addiss D. Direct assessment of the adulticidal efficacy of single dose ivermectin in bancroftian filariasis. Transactions of the Royal Society of Tropical Medicine and Hygiene 89:441-443, 1995.

15. Dreyer G, Norões J. Filariose bancroftiana: o reverso das alterações orgânicas. Jornal Brasileiro de Psiquiatria 47:227-231, 1998.

16. Dreyer G, Ottesen EA, Galdino E, Andrade L, Rocha A, Medeiros Z, Moura I, Cassimiro MI, Beliz MF, Coutinho A. Renal abnormalities in microfilaremic patients with bancroftian filariasis. American Journal of Tropical Medicine and Hygiene 46:745-751, 1992.

17. Dreyer G, Piessens W. Worms and microorganisms can cause lymphatic disease in residents of filariasis-endemic areas. In: Nutman TB (ed) Lymphatic Filariasis. $1^{\text {st }}$ edition, Imperial College Press, London, p. 245-264, 2000.

18. Dreyer G, Santos A, Norões J, Rocha A, Addiss D. Amicrofilaraemic carriers of adult Wuchereria bancrofti. Transactions of the Royal Society of Tropical Medicine and Hygiene 90:288-289, 1996.

19. Fan PC, Peng HW, Chen CC. Follow-up investigations on clinical manifestations after filariasis eradication by diethylcarbamazine medicated common salt on Kinmen (Quemoy) Island, Republic of China. Journal of Tropical Medicine and Hygiene 95:461-464, 1995.

20. Fundação Nacional de Saúde. Programa de eliminação da filariose linfática no Brasil. Seminário Internacional sobre Filariose Linfática. Ministério da Saúde, Brasília DF, 1997.

21. Medeiros Z, Gomes J, Beliz F, Coutinho A, Dreyer P, Dreyer G. Screening of army soldiers for Wuchereria bancrofti infection in metropolitan Recife region, Brazil: implications for epidemiologic surveillance. Tropical Medicine \& International Health 4:499-505, 1999.

22. Norões J, Addiss D, Amaral F, Coutinho A, Medeiros Z, Dreyer G. Occurrence of living adult Wuchereria bancrofti in the scrotal area of men with microfilaremia. Transactions of the Royal Society of Tropical Medicine and Hygiene 90:55-56, 1996.

23. Norões J, Addiss D, Santos A, Medeiros Z, Coutinho A, Dreyer $G$. Ultrasonographic evidence of abnormal lymphatic vessels in young men with adult Wuchereria bancrofti infection in the scrotal area. Journal of Urology, 156:409-412, 1996.

24. Norões J, Dreyer G, Santos A, Mendes VG, Medeiros Z, Addiss $D$. Assessment of the efficacy of diethylcarbamazine on adult Wuchereria bancrofti in vivo. Transactions of the Royal Society of Tropical Medicine and Hygiene 91:78-81, 1997.

25. Olszewski WL, Jamal S, Manokaran G, Pani S, Kumaraswami V, Kubicka U, Lukomska B, Dworczynski A, Swoboda E, Meisel-Mikolajczyk F. Bacteriologic studies of skin, tissue fluid, lymph, and lymph nodes in patients with filarial lymphedema. American Journal of Tropical Medicine and Hygiene 57:7-15, 1997. 
26. Ottesen EA, Duke BOL, Karam M, Behbehani K Strategies and tools for the control/elimination of lymphatic filariasis. Bulletin of the World Health Organization 75:491-503, 1997.

27. Rome RH, Fogel RH. The psychosomatic manifestations of filariasis. The Journal of the American Medical Association 123:944-946, 1943.

28. Seim AR, Dreyer G, Addiss D. Controlling morbidity and interrupting transmission: twin pillars of lymphatic filariasis elimination. Revista da Sociedade Brasileira de Medicina Tropical 32:325-328, 1999.
29. Shenoy RK, Sandhya K, Suma TK, Kumaraswami V. A preliminary study of filariasis related acute adenolymphangitis with special reference to precipitating factors and treatment modalities. Southeast Asian Journal of Tropical Medicine and Public Health 26:301-305, 1995.

30. World Health Organization. Strategies for control of lymphatic filariasis infection and disease. Report of a WHO/CTD/TDR consultative meeting held at the Universiti Sains Malaysia, Penang, (TDR/CTD/FIL/ PENANG/ 94.1). Malaysia, 22-24 August, 1994. 